\title{
Inversion and Evolution of Suspended Substance Concentration in Wuzhizhou Island Waters
}

\author{
Feng-Xia WANG ${ }^{1,2, a,{ }^{*}}$ and Hui-Hui YAN ${ }^{3, b}$ \\ ${ }^{1}$ State Key Laboratory of Marine Resources Utilization in the South China Sea, Haikou, China \\ ${ }^{2}$ College of Tourism, Hainan University, Haikou, China; \\ ${ }^{3}$ Sihong Hongze Lake Ecotourism Resort Management Committee, Sihong, China; \\ aSummer_wangfx@126.com, byanhh126@126.com \\ *Corresponding author
}

Keywords: suspended substance concentration; inversion model; remote sensing; Wuzhizhou Island

\begin{abstract}
Suspended matter is an important indicator of water environment monitoring. As a model of tropical tourist island in China, the content of the suspended substance influences the development of marine tourism. In order to understand the distribution of suspended matter concentration in Wuzhizhou Island, the correlation between the band combination and the concentration of suspended matter was analyzed by EXCEL and SPSS using TM data of Landsat-5 satellite and WFV2 image data of GF-1 satellite. The inversion model with high correlation level and good ufit was selected for estimation of suspended substance concentration. The results show that the polynomial regression model with the B2/B3 ratios of the Landsat-5 TM image on June 12010 is the best, and the B4 / B3 combination of GF-1 WFV2 data on June 2, 2014 is the best . The increase of the suspended matter concentration in Wuzhizhou Island area from 2010 to 2014, especially the northwest marine bathing area, the northern diving area and the maritime recreation area were affected by human tourism activities, and the suspended matter concentration changed obviously.
\end{abstract}

\section{Introduction}

Suspended substance (SS) is an important factor affecting the ecological environment of water. Suspension absorbs the light and scatters the content, then directly affects light transmission in the water, thereby affecting reproduction of submerged plants. Organic particles in suspension can provide nutrients for the marine organisms, which can cause changes in the concentration of nutrient salt [1]. With the rapid development of remote sensing technology, color remote sensing inversion studied by many scholars, remote sensing estimation method which was first used in terms of suspended solids. Foreign experts firstly simulated the turbidity and algal pigment concentration of freshwater lakes and river based on Landsat multispectral images [2, 3, 4]. Chinese experts built several inversion models of chlorophyll-a, suspended solids and other index based on the different kind's satellite data in different region $[5,6,7,8]$. Using remote sensing images to invert the concentration of Suspended solids become an important way for water quality monitoring. Research scholars at home and abroad over the concentration of suspended solids inversion aspects focused on the higher concentration of areas, such as inland rivers, lakes, while the studies on the concentration of suspended solids in the ocean were few. With a large number of launching remote sensing satellites, remote sensing inversion method will be gradually extended to in-depth research, and promote technological progress of remote sensing applications.

Suspended solids concentration inversion methods could be divided into empirical method [9, 10], analytical method [11], and semi-empirical method (semi-analytical method) [12]. The empirical model was easy to model construction and simple to calculate; contrast, the analytical method was too complicated calculation; and the semi-empirical method was susceptible to measurement errors of the optical area. Some experts solved problems of measured data for the suspended matter 
concentration of uncertainty factors by building an adaptive sampling consistency ELM inversion algorithm[13] and a discrete particle swarm-partial least squares inversion model to promote the accurate[14]. Many remote sensing image inversion algorithms, including the single band, and combinations band ratio, and BP neural network. In this research, band compositions was used to build suspended solids concentration inversion model in Wuzhizhou Island sea water, and to analyze the distribution of suspended solids concentration.

\section{Data Collection and Processing}

\section{Study Area and Real Data Mining}

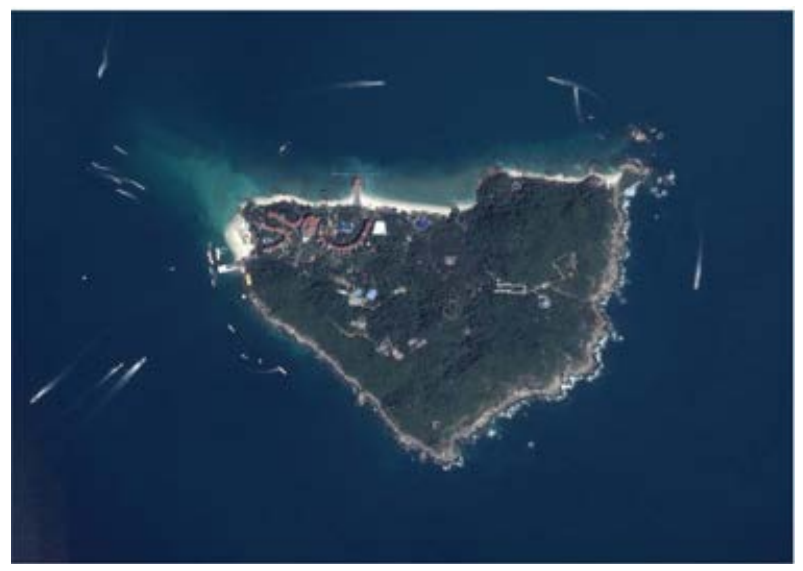

Fig. 1 The study area

Wuzhizhou Island $\left(109^{\circ} 45^{\prime} 42.60\right.$ "E $18^{\circ} 18^{\prime} 51.07$ "N) is located within Haitang Bay in tropical Hanan province, belonging to Sanya city and was called "Lovers Island". It has unique tropical island scenery, and is named national 5A level scenic spot. The largest distance between north and south is 1100 meters, with a radius of 1.48 square kilometers (see Fig. 1). According to the development of the situation Wuzhizhou Island waters, the study area was 1000 meters above sea level domain Wuzhizhou Island inshore, mainly for the development of marine tourism. Wuzhizhou Island coastal waters have bathing beach, diving area, entertainment area at sea, marine ranching areas and other marine tourism area.

The date of field sampling data of Wuzhizhou Island were June 11, 2010 and June 2, 2014. Investigations were made in 8 Survey stations (see Fig.2). The samples were collected in accordance with the "specification for oceanographic survey" and "marine monitoring" in, storage, transport and analysis, and according to weighing method to obtain concentration of suspended solids.

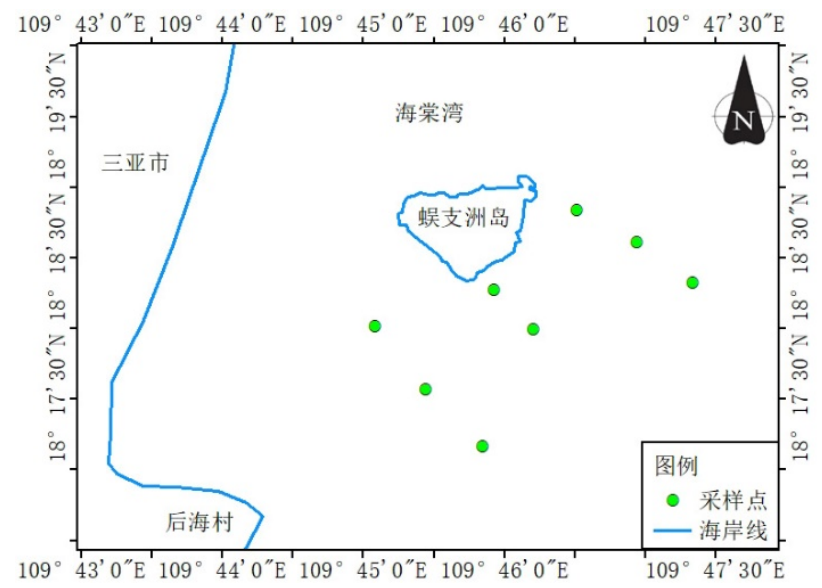

Fig. 2 Location distribution of field data acquisition 


\section{Remote Sensing Data \\ Remote Sensing Data Source}

The remote sensing images required for the comparison of suspended solids concentration in the sea area of Wuzhihzou Island were derived from TM images of Landsat-5 satellite on June 12, 2010 and WFV2 images of GF-1 satellite on June 3, 2014. The two kinds of data were both the multi-spectral images, with same WGS_84_UTM Spatial Reference System. The former spatial resolution was $30 \mathrm{~m}$, containing seven bands, while the latter spatial resolution was $16 \mathrm{~m}$ with four bands. The inversion was mainly applied in blue, green, red and near-infrared four bands, the spectrum range of the two is not very different and can be used for the study of inversion contrast.

\section{Image Processing}

The processing steps of remote sensing image data mainly included orthophoto correction, radiation correction, geometric correction and image clipping. Orthophoto correction was mainly to correct the deformation caused by the terrain, radiation correction was to eliminate the error of atmospheric absorption and scattering, geometric correction eliminated position, shape deformation, and cutting of the required research areas. Respectively, the function of RPC Orthorectification Using Reference Image in ENVI 5.3 was used for orthorectify, Radiometric Calibration for radiometric correction, FLAASH Atmospheric Correction for atmospheric correction, Select GCPs: Image to Image for geometric correction, and Subset Data from ROIs for image clipping.

\section{Sea Suspension Concentration Inversion in Wuzhizhou Island}

The correlation coefficient between the radiance brightness and suspended matter concentration of the images were calculated by Excel, which provided a reference for the later band combinations. The results showed that band-3 and band-4 had higher correlation coefficient with the concentration of suspended solids in 2010 images, while in2014, the correlation coefficient of band-2 was highest. By calculating the correlation coefficient, dependent variable band combinations were selected to facilitate the model.

\section{Suspension Concentration Retrieval Models}

By selecting corresponding band combination, and using the Excel and SPSS analysis of polynomial, linear, exponential, power, logarithmic and a series of mathematical function model, the correlation between various combination band and the suspended solids concentration was calculated with the index of level goodness-of fit $\mathrm{R}^{2}$, and $\mathrm{P}$ value. At last the optimal model was obtained. The results of the inversion model of Landsat-5 TM images in the sea area of Wuzhizhou island on June 11,2010 were shown in table 1 , where the significant correlation of each band combination of B3/B2, B2/B3, (B3+B4) had the $\mathrm{P}$ value less than 0.01 , reflecting the significant correlation. The value of $\mathrm{R}^{2}$ in $\mathrm{B} 2 / \mathrm{B} 3$ band ratio combined model was 0.967 with the best fit. As for the minimum value $\mathrm{P}$ means high significance level, the optimal inverse model was selected as follows:

$$
\mathrm{Y}_{\mathrm{L}-\mathrm{SS}}=0.477 \mathrm{X}_{\mathrm{L}}^{2}-2.282 \mathrm{X}_{\mathrm{L}}+10.70
$$

In the formula, $\mathrm{X}_{\mathrm{L}}=$ Band2/Band3 referred to the ratio of radiation luminance values in the second and third bands of Landsat-5 TM image; $Y_{\mathrm{L}-\mathrm{Ss}}$ referred to the suspended sliods concentration simulated by Landsat-5 TM image inversion in 2010, unit: mg /L. 
Table 1 Landsat TM estimation model for suspended sediment concentration in 2010

\begin{tabular}{|c|c|c|c|c|}
\hline $\begin{array}{l}\text { The dependent } \\
\text { variable }\end{array}$ & Arguments & $\mathrm{R}^{2}$ & P value & model \\
\hline $\mathrm{Y}_{\mathrm{L}-\mathrm{SS}}$ & $\mathrm{X}_{\mathrm{L}}=\mathrm{B} 3 / \mathrm{B} 2$ & 0.966 & $\begin{array}{c}0.001 \\
* *\end{array}$ & $\mathrm{Y}_{\mathrm{L}-\mathrm{SS}}=21.57 \mathrm{X}_{\mathrm{L}}^{2}-18.05 \mathrm{X}_{\mathrm{L}}+11.75$ \\
\hline $\mathrm{Y}_{\mathrm{L}-\mathrm{SS}}$ & $\mathrm{X}_{\mathrm{L}}=\mathrm{B} 2 / \mathrm{B} 3$ & 0.967 & $\begin{array}{c}0.000 \\
* *\end{array}$ & $\mathrm{Y}_{\mathrm{L}-\mathrm{SS}}=0.477 \mathrm{X}_{\mathrm{L}}^{2}-2.282 \mathrm{X}_{\mathrm{L}}+10.70$ \\
\hline $\mathrm{Y}_{\mathrm{L}-\mathrm{SS}}$ & $\mathrm{X}_{\mathrm{L}}=(\mathrm{B} 3+\mathrm{B} 4) / \mathrm{B} 2$ & 0.878 & $\begin{array}{c}0.005 \\
* *\end{array}$ & $\begin{array}{c}Y_{L-S S}=-0.730 X_{L}^{2}+0.898 X_{L}+ \\
7.775\end{array}$ \\
\hline $\mathrm{Y}_{\mathrm{L}-\mathrm{SS}}$ & $\begin{array}{c}\mathrm{X}_{\mathrm{L} 1}=\mathrm{B} 2 / \mathrm{B} 3, \mathrm{X}_{\mathrm{L} 2}=\mathrm{B} 2 / \\
\mathrm{B} 1\end{array}$ & 0.896 & - & $\begin{array}{c}\mathrm{Y}_{\mathrm{L}-\mathrm{SS}}=0.140 \mathrm{X}_{\mathrm{L} 1}-0.025 \mathrm{X}_{\mathrm{L} 2}+ \\
7.687\end{array}$ \\
\hline $\mathrm{Y}_{\mathrm{L}-\mathrm{SS}}$ & $\begin{array}{c}\mathrm{X}_{\mathrm{L} 1}=\mathrm{B} 1 / \mathrm{B} 2, \mathrm{X}_{\mathrm{L} 2}=\mathrm{B} 3 / \\
\mathrm{B} 2\end{array}$ & 0.883 & - & $\begin{array}{c}\mathrm{Y}_{\mathrm{L}-\mathrm{SS}}=0.037 \mathrm{X}_{\mathrm{L} 1}-0.892 \mathrm{X}_{\mathrm{L} 2}+ \\
8.335\end{array}$ \\
\hline
\end{tabular}

Note: * correlation 0.01 Significant level

The inversion model results of Wuzhizhou island waters in 2014 image were shown in table 2 with the band combinations of B4/B3, B2+B3, (B2+B3)/B1. The goodness of fit of all the model estimation were greater than 0.7 meaning better fit, but only the $\mathrm{P}$ value of $\mathrm{B} 4 / \mathrm{B} 3$ combination was less than 0.05 , with the maximum fit of $\mathrm{R}^{2}$ equaling 0.829 , showing the the significant correlation between the concentration of suspended matter and the band combination. Thus, remote sensing estimation model was selected as follows:

$$
\mathrm{Y}_{\mathrm{G}-\mathrm{SS}}=66.127 \mathrm{X}_{\mathrm{G}}^{2}-166.95 \mathrm{X}_{\mathrm{G}}+114.24
$$

In the formula, $\mathrm{X}_{\mathrm{G}}=$ Band4/Band3 referred to fourth-third bands radiance ratio in $2014 \mathrm{GF}-1$ WFV2 images; $\mathrm{Y}_{\mathrm{G}-\mathrm{SS}}$ referred to the inversion modeling value of suspension concentration, unit: $\mathrm{mg} / \mathrm{L}$.

Table 2 GF-1 WFV2 estimation model for suspended sediment concentration in 2014

\begin{tabular}{ccccc}
\hline The dependent variable & Arguments & $\mathrm{R}^{2}$ & $\mathrm{P}$ value & model \\
\hline $\mathrm{Y}_{\mathrm{G}-\mathrm{SS}}$ & $\mathrm{X}_{\mathrm{G}}=\mathrm{B} 4 / \mathrm{B} 3$ & 0.829 & $0.031 *$ & $\mathrm{Y}_{\mathrm{G}-\mathrm{SS}}=66.127 \mathrm{X}_{\mathrm{G}}{ }^{2}-166.95 \mathrm{X}_{\mathrm{G}}+114.24$ \\
$\mathrm{Y}_{\mathrm{G}-\mathrm{S}}$ & $\mathrm{X}_{\mathrm{G}}=\mathrm{B} 2+\mathrm{B} 3$ & 0.745 & 0.268 & $\mathrm{Y}_{\mathrm{G}-\mathrm{SS}}=4 \mathrm{E}-06 \mathrm{X}_{\mathrm{G}}{ }^{2}-0.0104 \mathrm{X}_{\mathrm{G}}+16.024$ \\
$\mathrm{Y}_{\mathrm{G}-\mathrm{SS}}$ & $\mathrm{X}_{\mathrm{G}}=(\mathrm{B} 2+\mathrm{B} 3) /$ & .7903 & 0.174 & $\mathrm{Y}_{\mathrm{G}-\mathrm{SS}}=-12.209 \mathrm{X}_{\mathrm{G}}{ }^{2}+46.721 \mathrm{X}_{\mathrm{G}}-35.346$ \\
$\mathrm{Y}_{\mathrm{G}-\mathrm{Ss}}$ & $\mathrm{X}_{\mathrm{G}}=(\mathrm{B} 2+\mathrm{B} 3) /$ & 0.699 & 0.347 & $\mathrm{Y}_{\mathrm{G}-\mathrm{SS}}=1.2858 \mathrm{X}_{\mathrm{G}}{ }^{2}-3.097 \mathrm{X}_{\mathrm{G}}+10.464$ \\
& $\mathrm{~B} 4$ & & & \\
\hline
\end{tabular}

Note: **Correlation0.05 Significant level

\section{Suspension Concentration Distribution and Evolution}

According to the structured sensing estimation model above, ENVI 5.3 Band Math tool was used to calculate the concentration of suspended solids, and ArcGIS10.3 was used to classified the suspended solids concentration grade of Wuzhizhou island waters. The concentration distribution of suspended solids results were shown in Table 3 and Fig. 3. Fig. 3 (a) showed the estimated suspended solids concentration on June 11, 2010, and Fig. 3 (b) showed the estimated distribution of suspended solids concentration on June 2, 2014.

Table 3 The proportion of total suspended matter concentration area in each in 2010 and 2014

\begin{tabular}{cccccccc}
\hline grade(mg / L) & $7.9-8.8$ & $8.8-9.4$ & $\begin{array}{c}9.4-10 . \\
0\end{array}$ & $10.0-12.4$ & $12.4-14.8$ & $14.8-17.1$ & $17.1-28$. \\
& & & 0 & & & 7 \\
\hline 2010In the area proportion & $90.43 \%$ & $7.37 \%$ & $1.25 \%$ & $0.89 \%$ & $0.04 \%$ & $0.02 \%$ & 0 \\
2014In the area proportion & 0 & $90.66 \%$ & $6.45 \%$ & $2.02 \%$ & $0.37 \%$ & $0.20 \%$ & $0.30 \%$ \\
\hline
\end{tabular}

According to table 3 and Fig. 3, the concentration of suspended solids in the Wuzhizhou island rised significantly by the of color blocks. The changes mainly included the following aspects: 

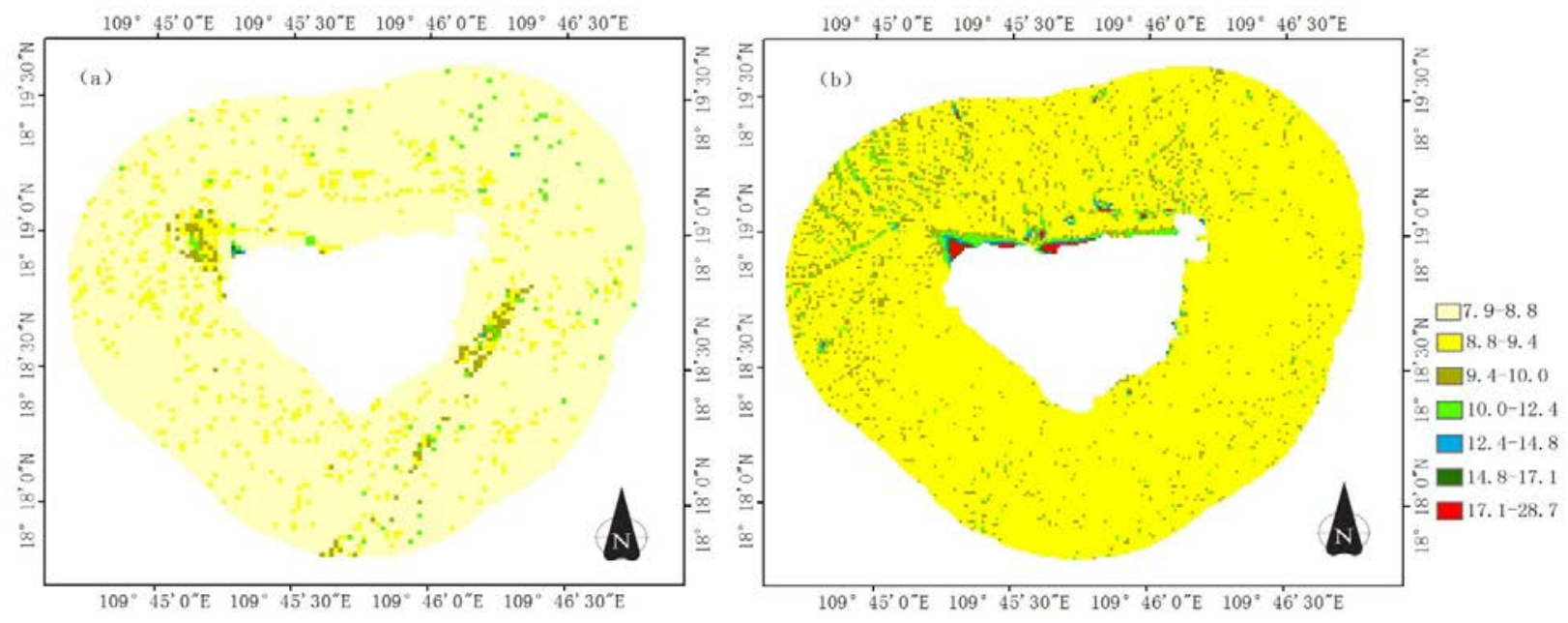

Fig. 3 Distribution of suspended sediment concentration (unit: mg / m3)

(1) Changes in the concentration range. On June 11, 2010, suspended solids concentration range was $7.9-17.1 \mathrm{mg} / \mathrm{L}$, while the concentration range of 2 June 2014 is $8.8-28.7 \mathrm{mg} / \mathrm{L}$. From the numerical perspective, the minimum value increased from 7.9 to 8.8 with the increase of 0.9 , while the maximum value increased 11.6. The numerical span was 9.2 in 2010, while 19.9 in 2014, which mean a significant increase in the scope of suspended solids concentration, minimum concentration and the maximum concentration.

(2) Change of the focus range. On June 11, 2010, 90.43\% of the suspended solids concentration of the study area focused in 7.9-8.8 $\mathrm{mg} / \mathrm{L}$, while on June 2, 2014, 90.66\% of the suspended solids concentration of study area focused on $8.8-9.4 \mathrm{mg} / \mathrm{L}, 0.3 \%$ of the area of concentration was greater than $17.1 \mathrm{mg} / \mathrm{L}$, showed in red color in Fig. 3(b).

(3) Change of the distribution area. The high concentration of suspended solids in the study area in 2010 was mainly concentrated in the offshore bathing area in the northeast coast of Wuzhizhou island, where tourists were concentrated; and the southeast area, where suspended solids concentration was also higher, showing a strip shape for there were a lot of subsea rocks with heavy projections and large waves, which easily caused the bottom sediments to form a large concentration of suspended solids from water upwelling zone. It was obvious in Fig. 3(b) in 2014. The suspended solids concentrated in the northwest sea water bath area, the northern diving area and the marine entertainment area of Wuzhizhou island, while the south and southeast parts had the lower value for the construction of marine ranch. The conflict between the reef and the waves slowed down, and the suspended matter concentration was relatively flat.

The reasons for the changes in coastal waters Wuzhizhou island concentration of suspended matter included the following two aspects:

(1) Natural factors. Hydrology, weather and other natural factors could influence the temperature of sea, $\mathrm{PH}$, frequency, height of storm, and utilization of nutrient salt. In particular typhoons, tropical storms and other natural weather. Rainfall would drive overland nutrients into the oceans, while temperature and nutrient salt would indirectly affect the breeding of marine organisms, thereby affecting changes in the concentration of suspended solids.

(2) Human factors. With the construction of the international tourism island, enhancing the level of tourist attractions, Wuzhizhou Island became well-known, loved by domestic and foreign tourists with increasion year by year. Extreme sports, diving, sea bath, yacht tourism activities expanded furtherly, which were easy to make the flowing of nutrient suspended solids in water, the water turbidity of suspended solids concentration increase. From 2010 marine ranch initial planning to gradually improved in 2014 in Wuzhizhou island, a lot of artificial reefs were put, which gradually improved bathing sediment, further formed the biosphere, made an increase in phytoplankton and animal species, would gradually affect the concentration of suspended solids. 


\section{Conclusion}

(1)Through the analysis of the correlation and fitting between the combination of remote sensing image bands and suspended solids concentration in Wuzhihzou Island, on 11 June 2010, the estimation model with the ratio of green light band and red light band as independent variable was superior to other remote sensing band combinations. On June 2, 2014, the ratio combination inversion model of near-infrared and red bands of regional remote sensing images was the best.

(2) From 2010 to 2014, the concentration of suspended solids of Wuzhizhou Island increased significantly, the suspended solids concentration changes of bathing beach and diving area in north, and sea tourist area in northwest were most obvious, mainly influenced by human tourism activities, which should cause the relevant departments to take measures to achieve sustainable development of man and nature.

\section{Acknowledgement}

The research is funded by Hainan Natural Science Foundation of China: Study on the Coupling Mechanisms between Tourism Development and Ecological Environment in Tropical Marine Ranch -take Wuzhizhou Island as an example(417068); Hainan Provincial Department of Education Project: Monitoring and Evaluation of Remote Sensing South China Sea Ranch environmental impact (Hnky2016ZD-6);

\section{References}

[1]LE Chengfeng, LI Yunmei, ZHA Yong, et al. The effect of suspended substance to the environment of water and its hyperspectral inversion in Tai Lake[J]. Journal of Environmental Science, 2008, 28 (10): 2148-2155.

[2] Carpenter DJ, Carpenter S M. Modeling inland water quality using Landsat data [J] Remote Sensing of Environment, 1983, 13 (4): 345-352.

[3] James PV Monitoring Water Quality Conditions In A Large Western Reservoir With Landsat Imagery [J] Photogrammetric Engineering and Remote Sensing, 1985, 51 (3):343-353.

[4] Somvanshi S, Kunwar P, Singh NB, et al Integrated remote sensing and GIS approach for water quality analysis of Gomti river, Uttar Pradesh [J] International Journal of Environmental Sciences, 2012 (1): 62-74.

[5]YANG Ting, ZHANG Hui, WANG Qiao, et al. Concentration inversion of chlorophyll -a and suspended substance based on HJ-1A hyperspectral satellite data [J]. Environmental Science, 2011, 32 (11): 3207-3214.

[6]HE Baoyin, ZHANG Wen, QIAO Xiaojing, et al. Study on the RS inversion of suspended substance concentration based on FOA-SVM method in Yangtze midstream [J]. Yangtze River Valley Resources and Environment, 2015,24 (4): 647-652.

[7]ZHAO Lina, WANG Yannan, JIN Qi, et al. Classified inversion of lake suspended substance concentration based on GOCI images [J]. Eco-Journal, 2015,35 (16): 5528-5536.

[8]ZHOU Zhou, ZHANG Wanlei, JIANG Wensheng, et al. Satellite inversion research on the surface suspended substance concentration in Bohai (2003-2014)[J]. Journal of Ocean University of China (Natural Sciences), 2017,47 (3): 10-18.

[9]YAN Mengdong, YANG Guofan, YIN Fei. Inversion models of total suspended solids concentration of in Qinghe reservoir based on Landsat images[J] Water Resources of rural China, 2016, (12): 74-78. 
[10]YANG Jingru, ZANG Shuying, HUI Hongkuan. Hyperspectral estimate model of the total suspended solids concentration in Harbin section of Songhua River[J]. Journal of Safety and Environment, 2014, (02): 239-243.

[11]LI Yunmei, HUANG Jiazhu, LU Wanning, SHI Junzhe. RS monitoring of suspended substance concentration based on analysis model [J] .Oceanologia Et Limnologia Sinica, 2006, (02): 171-177.

[12]LIU Zhonghua, LI Yunmei, TAN Jing, GUO Yulong, ZHOU Li, LIU Ge. semi-analytical inversion model and its adaptive model of total suspended solids concentration in Taihu and Chaohu Lake[J]. Environmental Sciences, 2012, (09): 3000-3008.

[13]AI Yeshuang, SHEN Yonglin. RS quantitative inversion method of suspended sediment concentration considering the measured uncertainty [J]. SPIE, 2016 (7): 10-20.

[14]CAO Yin, YE Yuntao, ZHAO Hongli, et al. RS inversion methods of suspended sediment concentration and turbidity in lake and reservoirs water sources based on discrete particle swarm and partial least squares method[J]. Hydroelectric Journal, 2015, 34 (11): 77-87. 